DEMINICIS, B.B. et al. Composição químico-bromatológica do feno de capim elefante amonizado com uréia. PUBVET, Londrina, V. 8, N. 13, Ed. 262, Art. 1738, Julho, 2014.

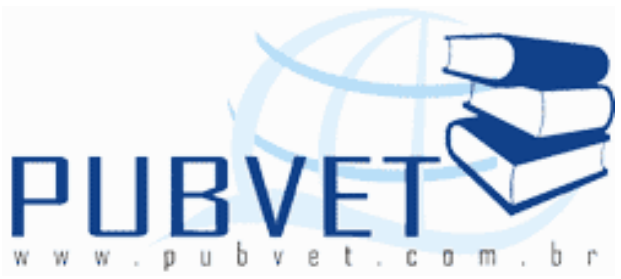

PUBVET, Publicações em Medicina Veterinária e Zootecnia.

\title{
Composição químico-bromatológica do feno de capim elefante amonizado com uréia
}

Bruno Borges Deminicis ${ }^{1}$, Rafael Pavesi Araújo ${ }^{2}$, Norberto Silva, Rocha ${ }^{3}$, Matheus Lima Corrêa Abreu ${ }^{2}$, Rafaela Neves Guerra ${ }^{4}$, Breno Ressari Nicolini ${ }^{5}$, Antônio Delunardo Pandolfi Filho ${ }^{4}$, Patricia do Rosário Rodrigues ${ }^{4}$

${ }^{1}$ Zootecnista, D.Sc. Prof.Dr. DZOO-CCA-UFES brunodeminicis@hotmail.com

'Zootecnista, Doutorando em Produção Animal da UENF/CCTA/LZNA,

${ }^{3}$ Zootecnista, Pós-Doutorando em Zootecnia da UFVJM.

${ }^{4}$ Zootecnista, Mestranda em Ciências Veterinárias da UFES.

${ }^{5}$ Zootecnista.

\section{Resumo}

O experimento foi realizado com objetivo de avaliar o efeito das diferentes doses de uréia na amonização do feno de capim elefante, sobre os teores de matéria seca (MS), proteína bruta (PB), fibra em detergente neutro (FDN), fibra em detergente acida (FDA), lignina (LIG), matéria mineral (MM), e Extrato Etéreo (EE). O delineamento experimental utilizado foi o inteiramente casualizado, com 6 tratamentos (doses) e 3 repetições. Os resultados demonstram que houve diferença entre teores de Proteína Bruta (PB) e Matéria Mineral (M.M), tendo sido observado maiores valores de PB para os tratamentos com maior porcentagem de ureia, em relação a MM ocorreu o inverso da PB, ou seja, os maiores percentuais de uréia adicionados ao feno proporcionaram menores valores sobre os teores de MM. Nos demais 
DEMINICIS, B.B. et al. Composição químico-bromatológica do feno de capim elefante amonizado com uréia. PUBVET, Londrina, V. 8, N. 13, Ed. 262, Art. 1738, Julho, 2014.

componentes avaliados MS, FDN, FDA, e LIG, não foram observadas diferenças entre as doses de uréia.

Palavras-chave: Amonização, Conservação de Forragem, Pennisetum purpureum

\title{
Chemical composition of elephant grass hay ammoniated with urea
}

\begin{abstract}
The experiment was conducted to evaluate the effect of different doses of urea ammoniation of elephant grass on the dry matter (DM), crude protein (CP), neutral detergent fiber (NDF), detergent fiber acidic (ADF), lignin (LIG), mineral matter (MM) and Ether Extract (EE). The experimental design was completely randomized with 6 treatments (doses) and 3 repetitions. The results showed that there were differences between levels of crude protein $(\mathrm{CP})$ and Mineral Matter (MM), observed higher $\mathrm{CP}$ for treatments with higher urea, compared to MM was the inverse of PB, ie, the highest percentages of urea added to hay provided lower values on the levels of MM. In the other components evaluated DM, NDF, ADF, and lignin, no differences were observed between doses of urea.
\end{abstract}

Keywords: Ammoniation, Forage Conservation, Pennisetum purpureum

\section{INTRODUÇÃO}

No Brasil existem duas estações climáticas bem definidas que causam uma enorme sazonalidade na produção. Dessa forma no período chuvoso as pastagens são subutilizadas, sobrando forragem. Em contrapartida no período seco do ano, há menor disponibilidade de forragem, faltando assim pastagens para os animais (SILVA et al, 2008). A sazonalidade de produção constituí um dos maiores desafios da pecuária brasileira (BERNARDINO et al, 2004), na qual o período seco interfere negativamente na produtividade do rebanho, tanto pela escassez de alimento como pela baixa qualidade (CRUZ et al, 2010). 
DEMINICIS, B.B. et al. Composição químico-bromatológica do feno de capim elefante amonizado com uréia. PUBVET, Londrina, V. 8, N. 13, Ed. 262, Art. 1738, Julho, 2014.

Para diminuir os efeitos da sazonalidade, é realizada a fenação da forragem no período de maior produção de capim, otimizando o manejo das pastagens e diminuindo os déficits quantitativos e qualitativos nas forragens produzidas (PÁDUA et al, 2008).

A técnica de fenação é uma das principais formas de conservação das forragens, juntamente com a silagem, tendo como objetivo suprir a necessidade de alimentos volumosos no período de inverno (abril a setembro), onde a maioria dos produtores não se prepara corretamente para suplementar os animais, causando enormes prejuízos no setor pecuário (CANDIDO et al., 1999). O capim elefante (Pennisetum purpureum) é uma das principais forragens utilizadas na alimentação de bovinos de corte e leite, que apresenta rápida adaptação as condições edafoclimáticas encontradas em regiões tropicais e alta quantidade de matéria seca (DESCHAMPS et al, 2001; CAMPOS et al, 2002).

Em contrapartida, o capim elefante é uma gramínea tropical $\mathrm{C}_{4}$, com maior eficiência no uso da energia solar e da água disponível, conferindo um metabolismo acelerado da planta que gera modificações na estrutura e composição da parede celular, afetando a digestibilidade da forragem (DESCHAMPS et al, 1999). De acordo com Salerno et al (1990), o capim elefante apresenta alta produtividade contudo, apresenta forte estacionalidade de produção, acompanhada da redução do valor nutritivo com o crescimento da planta. Para melhorar a qualidade da forragem fenada, são utilizados tratamentos químicos como o uso da amônia anidra (NH3) ou da uréia, sendo esse tratamento chamado de amonização. A uréia é a mais utilizada como fonte de amônia por apresentar fácil manuseio, grande disponibilidade no mercado, baixo risco de intoxicação humana e por ser menos onerosa que a amônia anidra (NEIVA et al, 1995; GOBBI et al., 2005).

A amonização promove alterações na composição química dos volumosos, aumentando o conteúdo de compostos nitrogenados e solubilizando a hemicelulose devido ao rompimento das pontes de hidrogênio e aumento da hidratação da fibra, permitindo rápido acesso dos 
DEMINICIS, B.B. et al. Composição químico-bromatológica do feno de capim elefante amonizado com uréia. PUBVET, Londrina, V. 8, N. 13, Ed. 262, Art. 1738, Julho, 2014.

microorganismos no rúmen, aumentando assim a digestibilidade (DOLBERG, 1992; REIS et al,1996). Objetivo do presente trabalho foi avaliar a composição químico-bromatológica do feno de capim elefante amonizado com diferentes doses de uréia.

\section{MATERIAL E MÉTODOS}

O experimento foi conduzido no Núcleo de Pesquisa em Zootecnia da Universidade Estadual Norte Fluminense (UENF), em Campos dos Goytacazes RJ, e no Laboratório de nutrição animal da Universidade Federal do Estado do Espirito Santo (UFES), Alegre - ES. O padrão climático da região Norte Fluminense é descrito como Aw, tropical quente úmido, com período seco no inverno e chuvoso no verão, segundo classificação de Köppen. O experimento foi conduzido entre novembro de 2010 à dezembro de 2011.

O plantio do capim-elefante cv. Napier (Pennisetum purpureum Schum.) foi feito em covas de $25 \mathrm{~cm}$ de profundidade com espaçamento entre linhas de $80 \mathrm{~cm}$, após o preparo do solo. O capim-elefante foi cortado manualmente com fação a uma altura de $10 \mathrm{~cm}$ e numa idade de 180 dias, e foi triturado em fragmentos de 0,5 a $2,0 \mathrm{~cm}$.

No entanto, somente foi aproveitada as folhas verdes e a parte superior do colmo. Após o corte, o material foi desidratado durante 72 horas, sendo realizados os processos de enleiramento e desenleiramento, com o objetivo de acelerar e uniformizar a desidratação. Em seguida o feno foi recolhido e transportado para as dependências do LZNA/UENF, onde foi realizada aplicação da uréia.

Foram aplicadas as seguintes doses: 0 (controle); 2, 4, 6, 8, 10\%, com base na matéria natural. O período de desidratação do feno foi estabelecido através da análise da plasticidade do material e da umidade. O material foi pesado na quantidade de $4 \mathrm{~kg}$ feno/saco sendo adicionadas nesse momento as doses de uréia de acordo com o tratamento, após a adição o material foi 
DEMINICIS, B.B. et al. Composição químico-bromatológica do feno de capim elefante amonizado com uréia. PUBVET, Londrina, V. 8, N. 13, Ed. 262, Art. 1738, Julho, 2014.

revolvido para melhor homogeneização entre o feno e a uréia. No momento da aplicação o feno apresentava 65\% de MS.

A uréia foi distribuída sobre a forragem previamente pesada, acondicionada em sacos plásticos, que foram misturados para obter uma maior homogeneização. Em seguida os sacos plásticos foram vedados de modo a impedir a perda da uréia aplicada por volatilização na forma de amônia. Após o período de armazenamento de 60 dias, os sacos foram abertos, permanecendo por 24 horas para eliminação da amônia produzida na hidrólise da uréia, em seguida retirou-se uma amostra de cada unidade experimental.

As amostras foram pesadas e colocadas em estufa de ventilação forçada de ar a $55^{\circ} \mathrm{C}$ durante 72 horas, posteriormente foram pesadas para determinação do teor de MS. As amostras foram moídas em moinho de facas do tipo Willey equipado com peneira para obtenção de partículas com granulometria de $1 \mathrm{~mm}$.

No Laboratório de Bromatologia Zootécnica do Departamento de Zootecnia da Universidade Federal do Espírito Santo (UFES), em Alegre-ES, o, foram realizadas análises Matéria seca (MS) e Proteína bruta (PB), Fibra em detergente neutro (FDN), Fibra em detergente acido (FDA), Lignina (LIG), Extrato Etéreo (EE) e Matéria Mineral (MM) segundo metodologias descritas por Silva e Queiroz (2002). Os tratamentos foram distribuídos segundo um delineamento inteiramente casualizado com 6 tratamentos (doses de uréia) e 3 (repetições), sendo os resultados analisados por regressão, utilizando o programa estatístico SISVAR (Ferreira, 1999).

\section{RESULTADOS E DISCUSSÃO}

De acordo com os dados apresentados na Tabela 1, pode-se observar que houve diferença significativa entre os tratamentos em relação os teores de Proteína Bruta (PB), Matéria Mineral (MM), de acordo com a análise da regressão. Contudo, não houve diferença significativa entre os tratamentos em 
DEMINICIS, B.B. et al. Composição químico-bromatológica do feno de capim elefante amonizado com uréia. PUBVET, Londrina, V. 8, N. 13, Ed. 262, Art. 1738, Julho, 2014.

relação aos teores de Matéria seca (MS), Fibra em detergente neutro (FDN), Fibra em detergente acido (FDA), Lignina (LIG) e Extrato etéreo (EE).

Tabela 1. Equações de regressão para as variáveis referentes à composição químico-bromatologica do feno de capim elefante amonizado com diferentes níveis de uréia $(0,2,4,6,8$ e 10\%), sendo estudados os teores Proteína Bruta (PB), Matéria Seca (MS), Fibra Detergente Neutro (FDN), Fibra Detergente Ácido (FDA), Lignina (LIG), Matéria Mineral (M.M) e Extrato Etéreo (E.E).

\begin{tabular}{cccc}
\hline Item & EQUAÇÃO & CV(\%) & $\mathbf{R}^{\mathbf{2}}$ \\
& & & \\
\hline PB & $\mathrm{Y}=1,3147 \mathrm{X}+6,0544$ & 1,85 & 0,95 \\
MS & $\mathrm{Y}=0,0714 \mathrm{X}+38,532$ & $4,61^{*}$ & 0,05 \\
FDN & $\mathrm{Y}=-0,7559 \mathrm{X}+83,616$ & $5,50^{*}$ & 0,85 \\
FDA & $\mathrm{Y}=-0,1176 \mathrm{X}^{2}+0,8048 \mathrm{X}+56,474$ & $7,70^{*}$ & 0,82 \\
HEM & $\mathrm{Y}=0,1069 \mathrm{X}^{2}-1,4535 \mathrm{X}+26,999$ & $7,81^{*}$ & 0,50 \\
LIG & $\mathrm{Y}=0,0151 \mathrm{X}^{2}-0,0993 \mathrm{X}+8,6428$ & $11,98^{*}$ & 0,29 \\
MM & $\mathrm{Y}=-0,0154 \mathrm{X}^{2}+0,0011 \mathrm{X}+6,4691$ & 8,67 & 0,94 \\
EE & $\mathrm{Y}=0,023 \mathrm{X}+0,9411$ & $7,68^{*}$ & 0,88 \\
\hline
\end{tabular}

*NS $=$ Os tratamentos foram não significativos

No momento da abertura das sacolas plásticas, com feno amonizado, para a coleta de amostras, não foi verificado o desenvolvimento de fungos nos tratamentos, na qual foram adicionados doses de uréia (2, 4, 6, 8 e 10\%), entretanto foi percebido fungos no tratamento controle $(0 \%)$. O presente trabalho encontrou resultados similares ao estudo de Reis et al (2001) em relação ao aparecimento de fungos, quando os mesmo autores avaliaram a composição química e digestibilidade de fenos tratados com amônia anidra ou 
DEMINICIS, B.B. et al. Composição químico-bromatológica do feno de capim elefante amonizado com uréia. PUBVET, Londrina, V. 8, N. 13, Ed. 262, Art. 1738, Julho, 2014.

aréia. Segundo o autor acima, provavelmente isto pode ser justificada pelo fato de que a uréia quando adicionada ao feno eleva o $\mathrm{PH}$.

No presente trabalho foi encontrado um efeito linear positivo nos teores de proteína bruta (PB \%), de acordo com a análise de regressão mostrada na tabela 1, onde doses de 0 (controle), 2, 4, 6, 8 e 10\% de uréia, obtiveram respectivamente $5,81,7,78,12,82,14,77,15,23$, e 19,36 \% teores de proteína bruta. Carvalho et al (2006) avaliando o bagaço de cana- de- açúcar amonizado com quatro doses de uréia, encontraram um aumento linear no teor de $\mathrm{PB}(\%)$ com a inclusão de doses de uréia, esse aumento é explicado pela adição de nitrogênio não proteico (NNP) no bagaço de cana, resultando num aumento de nitrogênio total, computado como PB(\%).

Schimit et al (2003), estudando feno de braquiaria amonizado com uréia ou inoculado com Pleutotus ostreatus, encontraram uma correlação positiva entre doses de uréia e teor de proteína, com aumento das doses de uréia, foi verificado aumento dos teores de proteína bruta, de acordo com os tratamentos. Faria et al (2008) avaliando a composição bromatológica do coproduto do desfibramento do sisal tratado com uréia, encontraram resultados similares, onde os teores médios de $\mathrm{PB}(\%)$ aumentaram linearmente em função da aplicação de doses crescentes de uréia, sendo esse aumento justificado pela adição de nitrogênio não proteico (NNP) no co-produto.

Pádua et al (2008) estudando a grama babatais (Paspalum notatum) submetida à amonização, encontraram também uma elevação do teor de proteína em função do aumento das doses de uréia aplicada, sendo esse comportamento explicado pela deposição de nitrogênio não proteico (NNP), aplicado na forma de uréia, no tecido vegetal. De acordo com Schimit et al (2003) o aumento nos teores de proteína via amonização, está relacionada com a retenção de nitrogênio, e esta, à atividade ureolítica responsável pela transformação da uréia em amônia.

Souza et al (2002) explicam que a retenção do $\mathrm{N}$ pode ser causada por dois fatores, o primeiro é que $\mathrm{N}$ é retido por meio de uma reação da amônia com a água presente nos materiais. O segundo fator é que a amônia e um 
DEMINICIS, B.B. et al. Composição químico-bromatológica do feno de capim elefante amonizado com uréia. PUBVET, Londrina, V. 8, N. 13, Ed. 262, Art. 1738, Julho, 2014.

éster podem sofrer uma reação, chamada de amonolise produzindo uma amida. Carvalho et al (2006) diz que embora as doses de uréia causam um aumento significativo nos teores de $\mathrm{PB}(\%)$, isto não significa que seja pertinente adicionar altas doses de uréia, NNP, pois isto excede a necessidade dos ruminantes.

No presente trabalho foram encontrados níveis maiores de proteína bruta quando foram adicionadas maiores doses de uréia nos tratamentos. Com a adição de $2 \%$ de uréia no feno de capim elefante, foi observado $7,78 \%$ de PB, nível maior que o nível mínimo exigido para um bom funcionamento do rúmen, que é de 7\% de PB. Santos et al (2001) avaliando o uso de nitrogênio não proteico na alimentação de vacas leiteiras, constataram que 7\% PB é essencial para manter uma atividade microbiana ativa.

Os resultados observados no presente estudo proporcionaram, respectivamente com adição de 4, 6, 8 e 10\% de uréia, um teor de 12,82, $14,77,15,23$ e 19,36 \% de PB, valores muito maiores para um bom funcionamento do rúmen. Esses valores podem contribuir para um aumento da população de microorganismos presentes no rúmen, aumentando assim, a eficiência no aproveitamento dos alimentos segundo Carvalho et al (2006).

De acordo com a tabela 1 , os teores de matéria seca (MS \%) apresentaram um efeito linear positivo de acordo com a análise de regressão, assim os tratamentos com 0, 2, 4, 6, 8 e 10\% de uréia, proporcionaram respectivamente $38.33,38.33,39.59,39.80,39.88$ e $40.00 \%$ de matéria seca, evidenciando que os maiores valores de uréia obtiveram os maiores valores de matéria seca no feno de capim elefante amonizado.

De acordo com Rosa et al (2001) a uréia tem um alto poder higroscópico, ou seja, apresenta alta afinidade com água assim, fenos amonizados apresentam menor teor de matéria seca (MS\%) quando comparados com fenos não tratamentos. O presente trabalho corrobora com as afirmações do autor acima, onde os fenos tratados com uréia apresentaram uma média de 39,32\% de matéria seca, muito diferente de Aguiar et al (2006) avaliando o rendimento e composição de fenos triturados de gramíneas 
DEMINICIS, B.B. et al. Composição químico-bromatológica do feno de capim elefante amonizado com uréia. PUBVET, Londrina, V. 8, N. 13, Ed. 262, Art. 1738, Julho, 2014.

tropicas, que encontraram valores em torno de 90,65 \% de matéria seca de fenos de capim elefante não tratados com uréia. Segundo Rosa et al (2001) a alta afinidade da amônia com a água promove a expansão da parede celular e ruptura de componentes dos tecidos de forragens amonizadas, que podem ser constatados por meio de estudos de microscopia eletrônica.

Na tabela 1 mostra que houve um efeito linear negativo nos teores de FDN de acordo com a equação de regressão, ou seja, as doses de 0, 2, 4, 6, 8 e $10 \%$ de uréia, proporcionaram respectivamente $84.25,81.25,79.26,80.89$, 78.07 e $75.26 \%$ de FDN dentro dos tratamentos.

De acordo com Van Soest (1994), concentrações de Fibra em detergente neutro (FDN) acima de $60 \%$ na dieta proporcionam uma correlação negativa com o consumo de matéria seca de espécies forrageiras. No presente trabalho os valores encontrados em todos tratamentos são maiores que $60 \%$, apresentando uma média de 79,83 \% FDN, portanto todos tratamentos de acordo com o autor acima podem diminuir o consumo de matéria seca. Dutra et al (1997) avaliando os efeitos dos níveis de fibra e das fontes de proteínas sobre o consumo e digestão de nutrientes em novilhos, observaram que dietas com altas porcentagens de FDN promoveram redução no consumo de MS, devido a limitação provocada pelo enchimento do rúmen- retículo do ruminante.

Reis et al (2003) avaliando o valor nutritivo do feno de capim coast-cross submetido a amonização, não verificou diferença nos valores de FDN entre os tratamentos com vários níveis de uréia. A verificação da ineficiência da uréia pode ser explicada por dois fatores, o primeiro é a alta taxa de umidade do capim elefante, e o outro é a colheita do capim no estádio de desenvolvimento avançado (180 dias), que pode ter afetado a atividade da uréase, diminuindo a liberação de amônia, e assim diminuir a solubilização da hemicelulose (Dolberg, 1992).

No presente estudo foi constatado através da análise de regressão, um efeito quadrático em relação aos teores de FDA, assim as doses de 0 (controle), 2, 4, 6, 8 e 10\% de uréia, proporcionaram respectivamente 56.26, 
DEMINICIS, B.B. et al. Composição químico-bromatológica do feno de capim elefante amonizado com uréia. PUBVET, Londrina, V. 8, N. 13, Ed. 262, Art. 1738, Julho, 2014.

$57.37,59.08,56.78,54.16$ e $53.46 \%$ de FDA, corroborando com os resultados observados por Sarmento et al (1999), avaliando o tratamento do bagaço de cana-de- açúcar com uréia. Os mesmos autores justificam que este fato ocorre porque provavelmente a amônia não altera as frações de celulose e lignina, que são constituintes do FDA. Fernandes et al (2002) também não encontraram diferença nos teores de FDA, quando avaliou a qualidade do feno de Brachiaria decumbens submetido ao tratamento com amônia anidra ou ureia. Reis et al (1993) avaliando a amonização do feno de Brachiaria decumbens com diferentes teores, também não observou efeito da amonização sobre os teores de FDA.

Grossi et al (1993) avaliando o tratamento de volumosos com amônia anidra ou uréia, constataram que não houve diferença nos valores de FDA dentro dos tratamentos, em que a palha de aveia e a casca de arroz apresentam umidade maior que $10 \%$. Essa umidade provavelmente limitou a liberação da amônia a partir da hidrólise da uréia. Esse processo ocasionalmente ocorre com o capim elefante fenado, onde o mesmo apresenta uma umidade em torno de $30 \%$, limitando assim a ação da uréia, não afetando os valores de FDA.

A parede celular apresenta duas principais estruturas (celulose e hemicelulose) que são as maiores fontes de substrato disponível no rúmen para a fermentação, e constituem a principal fonte de energia para os ruminantes, porém sua qualidade pode ser afetada com a presença de lignina, que apresenta uma correlação negativa com a digestibilidade (Bauer et al, 2008). Os resultados da composição químico-bromatológica verificado no presente estudo corroboram com a afirmação de Campos et al (2002) na qual o autor propõe que o avanço da idade fisiológica da planta aumentam as porcentagens de lignina, celulose e hemicelulose, reduzindo assim a digestibilidade da matéria seca principalmente em gramíneas tropicais, interferindo decisivamente na utilização desse alimento para os ruminantes.

No presente trabalho ocorreu um efeito quadrático de acordo com análise de regressão em relação aos teores de lignina, onde as doses de 0, 2, 4, 6, 8 e 
DEMINICIS, B.B. et al. Composição químico-bromatológica do feno de capim elefante amonizado com uréia. PUBVET, Londrina, V. 8, N. 13, Ed. 262, Art. 1738, Julho, 2014.

$10 \%$ de uréia, proporcionaram respectivamente $8.85,7.94,8.99,8.27,9.08$ e 9.04\% de lignina no feno de capim elefante amonizado.

Gobbi et al (2005) afirmam que as respostas no teor de lignina de volumosos em relação à amonização é bastante variável e contraditória. Gobbi et al (2005), avaliando a composição química e digestibilidade in vitro do feno de Brachiaria decumbens Staf tratado com uréia, também não encontrou diferença entre os tratamentos sobre os teores de lignina. Morais et al (2004) encontrou valores de lignina em fenos de capim elefante de 5,71\%, Aguiar et al (2006) avaliando o rendimento e a composição químico-bromatológica de fenos triturados de gramíneas tropicais, encontrou valores em torno de 5,26\%. Nesse experimento o menor valor de lignina foi encontrado no tratamento de $2 \%$ de uréia $(7,94 \%)$, esse fato provavelmente pode ser explicado pelo alto grau de maturação da forragem (180 dias), lignificando os constituintes da parede celular da gramínea tropical.

No presente trabalho foi encontrado através da análise de regressão, mostrada na tabela 1 que houve efeito quadrático nos teores de matéria mineral (MM\%), ou seja, as doses com 0, 2, 4, 6, 8 e $10 \%$ de uréia, proporcionaram respectivamente $6.45,6.40,6.35,5.69,5.65$ e $4.90 \%$ de matéria mineral, assim foi verificado que os maiores valores de uréia ( $8 \%$ e $10 \%$ ) adicionados ao feno de capim elefante cv. Napier (Pennisetum purpureum Schum.), proporcionaram uma diminuição na matéria mineral do feno de capim elefante. Rosa et al (2000) encontraram os mesmos resultados, quando avaliaram a composição química do feno de Brachiaria brizantha cv.Marandu tratado com diferentes proporções de uréia e de água, onde as doses maiores (6\% de uréia) apresentaram menores valores de matéria mineral (M.M).

No presente trabalho os valores encontrados nos teores de EE (\%) segue um efeito quadrático de acordo com a análise de regressão, assim as doses de $0,2,4,6,8$ e10\% de uréia, proporcionaram respectivamente $0.98,0.98,0.98$, $1.07,1.11,1.20 \%$ de $E E$, oscilando em torno de $1,05 \%$, sendo considerado um valor baixo e importante, pois não comprometem a digestiblidade da matéria 
DEMINICIS, B.B. et al. Composição químico-bromatológica do feno de capim elefante amonizado com uréia. PUBVET, Londrina, V. 8, N. 13, Ed. 262, Art. 1738, Julho, 2014.

seca. De acordo com Van Soest (1994) altos valores de EE (\%) em dietas para ruminantes comprometem a digestibilidade e o consumo de forragens, desta forma não devem ultrapassar 7\% de EE (\%) na dieta total. Vasconcelos (1997) avaliando a caracterização química e degradação de forrageiras do semi-árido brasileiro no rúmen de caprinos observou que altos teores de extrato etéreo (EE \%) provocam efeitos deletérios sobre os microorganismos do rúmen. Reis et al (2000) estudando a composição química, consumo voluntário e digestiblidade de silagens de resíduos do fruto de maracujá e de capim elefante, verificou que altos teores de EE (\%) afetam a digestibilidade da matéria seca, e conseqüentemente atrapalha o consumo de alimento volumoso por parte do animal.

\section{CONCLUSÃO}

A amonização do feno de capim elefante proporcionou melhor qualidade do material, em razão ao aumento da proteína bruta nos tratamentos, mais em relação aos teores de FDN, FDA, LIG e M.M não ocorreram melhoras, houve apenas a manutenção dos teores. Como o capim elefante foi fenado com uma idade avançada, 180 dias, os constituintes da parede celular estavam muito lignificados, reduzindo o efeito da amônia sobre as fibras da forragem.

\section{REFERÊNCIAS BIBLIOGRÁFICAS}

AGUIAR, E.M.; LIMA, G.F. C.; SANTOS, M.V. F.; CARVALHO, F.F.R.; GUIM, A.; MEDEIROS, H.R.; BORGES, A.Q. Rendimento e Composição Químico-Bromatológica de Fenos Triturados de Gramíneas Tropicais. In: Revista Brasileira de Zootecnia, v.35, n.6, p.2226-2233, 2006.

BAUER, M.O.; GOMIDE, J.A.; SILVA, E.A.M.; REGAZZI, A.R.; CHICHORRO, J.F. Características anatômicas e valor nutritivo de quatro gramíneas predominantes em pastagem natural de Viçosa, MG. In: Revista Brasileira de Zootecnia, v.37, n.1, p.9-17, 2008.

BERNARDINO, F.S.; CAMPOS, M.C.L.; ROCHA,F.C.; GARCIA.R.; CAMPOS, O.F.; GOBBI,K.F. Amonização de Feno de Alfafa com Alta Umidade. Anais da Reunião Anual da Sociedade Brasileira de Zootecnia, 2004-Campo Grande, MS. 
CAMPOS, F.P.; SARMENTO, P.; LANNA, D.P.D.; BOSE, M.L.V.; BOIN, C. Degradabilidade do Capim-Elefante em Diferentes Estagios de Maturidade avaliada pelo Método In Vitro/Gás. In: Scientia Agricola, v.59, n.2, p.217-225, abr/jun.2002.

CÂNDIDO, M.J.D.; NEIVA, J.N.M.; PIMENTEL, J.C.M. et al. Avaliação do valor nutritivo do bagaço de cana-de-açúcar amonizado com uréia. In: Revista Brasileira de Zootecnia, v.28, n.5, p.928-935, 1999.

CARVALHO, G.G.P.; PIRES, A.J.; VELOSO, C.M.; MAGALHÃES, A.F. et al. Valor nutritivo do bagaço de cana-de-açúcar amonizado com quatro doses de ureia. In: Revista Agropecuária Brasileira, v.41, n.1, p.125-132, 2006.

CRUZ, I.V.P.; SANTOS, L.L.; BACKES, A.A.; FAGUNDES, J.L.; GÓIS, K.C.R.; OLIVEIRA, R.S. Qualidade do Feno de Maniçoba (Maninhot pseudoglaziovii) com ou sem adição de feno de capim elefante. In: 47a Reunião Anual da Sociedade Brasileira de Zootecnia, 27 a 30 de Julho de 2010; Salvador-BA.

DESCHAMPS, F.C. Implicações do período de crescimento na composição química e digestão dos tecidos de cultivares de capim elefante. In: Revista Brasileira de Zootecnia, v. 28, n.6, p.1178-1189, 1999.

DESCHAMPS, F.C. Qualidade da forragem e participação relativa na produção de matéria seca de diferentes frações de cultivares de capim elefante(Pennisetum purpureum Schumach.). In: Revista Brasileira de Zootecnia, v.30, p.1418-1423, 2001.

DOLBERG.; F. Program in the utilization of urea - ammonia treated crop residues: nutritional dimensions and application of the technology on small farm. In: SIMPÓSIO INTERNACIONAL DE RUMINANTES, 1992, Lavras. Anais... Lavras: Sociedade Brasileira de Zootecnia, 1992. p.130-145.

DUTRA, A.G.; QUEIROZ, A.G.C.; PEREIRA, J.C.; VALADARES, S.C.F et al. Efeitos dos níveis de fibra e das fontes de proteínas sobre o consumo e digestão dos nutrientes em novilhos. In: Revista Brasileira de Zootecnia, v.26, n.4, p.787-796, 1993.

FARIA, M.M.S.; JAEGER, S.M.P.L.; OLIVEIRA, G.J.C.; LEDO, C.A.S.; SANTANA, F.S. Composição bromatológica do co-produto do desfibramento do sisal tratado com uréia. In: Revista Brasileira de Zootecnia, v.37, n.3, p.377-382, 2008.

FERNANDES, L.O.; REIS, R.A.; RODRIGUES, L.R.A. et al. Qualidade do feno de Brachiaria decumbens Stapf. Submetido ao tratamento com amônia anidra ou uréia. In: Revista Brasileira de Zootecnia, v.31, n.3, p. 1325-1332, 2002.

FERREIRA, D.F. 1999. SISVAR 4.3. Sistema de análises estatísticas. CD ROM. Universidade Federal de Lavras, UFLA. Lavras, MG.

GROSSI, S.F.; REIS, R.A.; EZEQUIEL, J.M.B.; RODRIGUES, L.R.A.; Tratamento de Volumosos com Amônia Anidra ou Uréia. In: Revista Brasileira de Zootecnia, v.22, p.651-660, 1993.

GOBBI, K.F., Garcia, R., Garcez Neto, A. F., Pereira, O.G., Bernardino, F.S.; Rocha, F.C. Composição química e digestibilidade in vitro do feno de Brachiaria decumbens Stapf. Tratado com uréia. In: Revista Brasileira de Zootecnia, v. 34, p. 720-725,2005.

MORAIS, J.A.S.; KOZLOSKI, G.V.; REFFATTI, M.V. et al. Nível de consumo e sua relação com o valor nutritivo do feno de capim-elefante anão (Pennisetum purpureum Schum. cv. Mott) oferecido a ovinos. In: REUNIÃO ANUAL DA SOCIEDADE BRASILEIRA DE ZOOTECNIA, 41., 2004, Campo Grande. Anais... Campo Grande: Sociedade Brasileira de Zootecnia.

NEIVA, J. N. M.; GARCIA, R. Utilização da amonização na melhoria da qualidade de volumosos para ruminantes. In: SIMPÓSIO NORDESTINO DE ALIMENTAÇÃO DE RUMINANTES, 5. 1995, Salvador. Anais... Salvador: Sociedade Nordestina de Produção Animal, 1995. p. 4161. 
PÁDUA, F.T.1, Almeida, J.C.C., Nepomuceno, D.D., Cabral Neto, O. e Deminicis, B.B. Efeito da Dose de Uréia e Periodo de Tratamento sobre a Composição do Feno de Paspalum notatum. In: Archivos de Zootecnia vol.60, n. 229, p.58, 2008.

REIS, R.A.; RODRIGUES, L.R.A.; BONJARDIM, E.N.S.R.; PEREIRA, J.R.A. Amonização do Feno de Brachiaria decumbens com Diferentes Teores de Umidade. In: Pesquisa Agropecuária Brasileira, v.28, n.4, p.539-543, 1993.

REIS, R.A.; RODRIGUES, L.R.A.; PEREIRA, J.R.A. Sementes de gramíneas forrageiras. In: SIMPÓSIO SOBRE NUTRIÇÃO DE BOVINOS, 06., 1996, Piracicaba. Anais... Piracicaba: Fundação de Estudos Agrários "Luiz de Queiroz", 1996.p.259-280.

REIS, J.; PAIVA, P.C.A.; TIESENHAUSEN, I.M.E.Y.; RESENDE, C.A.P. Composição química, consumo voluntário e digestibilidade de silagens de resíduos do fruto de maracujá (Passiflora edulis Sims f. flavicarpa) e de capim-elefante (Pennisetum purpureum, Schum.) cv. Cameroon e suas combinações. In: Revista Ciência Agrotecnol, v. 24, n.1, p. 213224, 2000.

REIS, R. A.; RODRIGUES, L.R.A.; PEREIRA, J.R.A. et al. Composição química e digestibilidade de fenos tratados com amônia anidra ou uréia. In: Revista Brasileira de Zootecnia, v.30, n.3, p.666-673, 2001a.

REIS, R. A.; RODRIGUES, L.R.A.; RESENDE, K.T. et al. Avaliação de fontes de amônia para o tratamento de fenos de gramíneas tropicais. 1. Constituintes da parede celular, poder tampão e atividade ureática. In: Revista Brasileira de Zootecnia, v.30, n.3, p.674-681, 2001b.

REIS, R.A.; RODRIGUES, L.R.A.; RESENDE, K.T. et al. Avaliação de fontes de amônia para o tratamento de fenos de gramíneas tropicais. 2. Compostos nitrogenados. In: Revista Brasileira de Zootecnia, v.30, n.3, p.682-686, 2001c.

ROSA, B.; SOUZA, H.; RODRIGUES, K.F. Composição química do feno de Brachiaria brizantha cv. Marandu tratado com diferentes proporções de uréia e de água. In: Revista Ciência Animal Brasileira, v.1, n.2, p. 107-113, 2000.

ROSA, B.; FADEL, R. Uso de amônia anidra e de uréia para melhorar o valor alimentício de forragens conservadas. In: SIMPÓSIO SOBRE PRODUÇÃO E UTILIZAÇÃO DE FORRAGENS CONSERVADAS, 2001, Maringá. Anais... Maringá: Simpósio Sobre Produção e Utilização de Forragens Conservadas / Editores Clóves Cabreira Jobim, Ulysses Cecato, Júlio César Damasceno e Geraldo Tadeu dos Santos, 2001. P.41-68.

SALERNO, A.R.; VETTERLE, C.P.; DESCHAMPS, F.C. FREITAS, E.A.G. Gramíneas forrageiras estivais perenes no Baixo Vale do Itajaí. Boletim Técnico n. 49. Empresa de Pesquisa Agropecuária de Santa Catarina, Florianópolis, 1990.

SANTOS, G.T.; CAVALIERI, F.L.B.; MODESTO, E.C. Recentes avanços em nitrogênio não protéico na nutrição de vacas leiteiras. In: SINLEITE, 2., 2001, Lavras. Anais.... Lavras: Ufla, 2001. p.199-228.

SARMENTO, P.; GARCIA, R.; PIRES, A.J.V.; NASCIMENTO, A.S. Tratamento do bagaço de cana de açúcar com uréia. In: Revista Brasileira de Zootecnia, v.28, p.1203-1208, 1999.

SCHIMIT, P.; WECHSLER, F.S.; JUNIOR, F.M.V.; ROSSI, P. Valor nutritivo do feno de Braquiária Amonizado com ureia ou inoculado com Pleurotus ostreatus In: Revista Brasileira de Zootecnia, v.32, n.6, p.2040-2049, 2003

SILVA, H.G.O.; PIRES, A.J.V.; CARVALHO, G.G.P.; VELOSO, C.M. et al. Capim-elefante amonizado e farelo de cacau ou torta de dendê em dietas para ovinos em crescimento. In: Revista Brasileira de Zootecnia, v.37, p.734-742, 200

SILVA, D.J.; QUEIROZ, A.C. Análise de Alimentos: Métodos Químicos e Biológicos. $3^{\circ}$ edição. Viçosa. 2009. 235 p. 
SOUZA, A.L.; GARCIA, R.; PEREIRA, O.G.; CECON, P.R.; PIRES, A.J.V.; LOURES, D.R.S. Valor nutritivo da casca de café tratada com amônia anidra. In: Revista Ceres, v.26, p.669-681, 2002.

VAN SOEST.; P.J. Nutritional ecology of theruminant. Cornell University. Ithaca. 476 pp. 1994.

VASCONCELOS, V.R. Caracterização química e degradação de forrageiras do semi-árido brasileiro no rúmen de caprinos. 132p. Tese (Doutorado em Zootecnia) - Faculdade de Ciências Agrárias e Veterinárias/Universidade Estadual Paulista, 1997. 